University of Nebraska - Lincoln

DigitalCommons@University of Nebraska - Lincoln

Sociology Department, Faculty Publications

Sociology, Department of

$11-2001$

\title{
Deviant Behavior and Victimization Among Homeless and Runaway Adolescents
}

\author{
Les B. Whitbeck \\ University of Nebraska-Lincoln, Iwhitbeck2@unl.edu \\ Dan R. Hoyt \\ University of Nebraska-Lincoln, dhoyt2@unl.edu \\ Kevin A. Yoder \\ lowa State University \\ Ana Mari Cauce \\ University of Washington \\ Matt Paradise \\ University of Washington
}

Follow this and additional works at: https://digitalcommons.unl.edu/sociologyfacpub

Part of the Sociology Commons

Whitbeck, Les B.; Hoyt, Dan R.; Yoder, Kevin A.; Cauce, Ana Mari; and Paradise, Matt, "Deviant Behavior and Victimization Among Homeless and Runaway Adolescents" (2001). Sociology Department, Faculty Publications. 94.

https://digitalcommons.unl.edu/sociologyfacpub/94

This Article is brought to you for free and open access by the Sociology, Department of at DigitalCommons@University of Nebraska - Lincoln. It has been accepted for inclusion in Sociology Department, Faculty Publications by an authorized administrator of DigitalCommons@University of Nebraska - Lincoln. 
Published in Journal of Interpersonal Violence 16:11 (November 2001), pp. 1175-1204; doi: 10.1177/088626001016011005 Copyright (C 2001 Sage Publications; published on behalf of the American Professional Society on the Abuse of Children.

Used by permission. http://jiv.sagepub.com/cgi/content/abstract/16/11/1175

The Seattle Homeless Youth Project is supported by NIAAA Grant No. AA10253, Ana Mari Cauce, principal investigator. The Midwest Homeless and Runaway Adolescent Project was supported by NIMH Grant No. MH50140, Les B. Whitbeck, principal investigator.

\title{
Deviant Behavior and Victimization Among Homeless and Runaway Adolescents
}

\author{
Les B. Whitbeck \\ Dan R. Hoyt \\ University of Nebraska-Lincoln \\ Kevin A. Yoder \\ Iowa State University \\ Ana Mari Cauce \\ Matt Paradise \\ University of Washington
}

\begin{abstract}
This study used a high-risk population of runaway and homeless adolescents to investigate the effects of history of caretaker abuse and deviant subsistence strategies on victimization among adolescents. Based on a multisite sample of 974 homeless and runaway adolescents, logistic regression models were used first to examine factors predicting involvement in sexual and nonsexual deviant subsistence strategies and then to investigate the effects of deviant subsistence strategies on physical and sexual victimization when adolescents were on the streets. Results indicated that when controlling for all other factors, including histories of physical and sexual maltreatment in families of origin, street behaviors, sexual orientation, and informal support systems, engaging in nonsexual deviant subsistence strategies increased the likelihood of physical victimization more than two times. Engaging in sexual deviant subsistence strategies increased the likelihood of sexual victimization almost four times. The results are interpreted in terms of life course developmental theory and lifestyle exposure theories.
\end{abstract}

Theories of adolescent victimization typically focus on exposure to risk, such as proximity to predators, or on the link between participation in deviant behaviors and exposure to danger (Jensen \& Brownfield, 1986; Lauritsen, Sampson, \& Laub, 1991; Sampson \& Lauritsen, 1990). Activities that involve even minor deviance (e.g., drinking and going to bars) increase victimization rates (Jensen \& Brownfield, 1986). When adolescents 
engage in more serious deviance, such as violent behaviors, risk increases dramatically (Sampson \& Lauritsen, 1990). Running away and living on one's own is a form of adolescent deviant behavior that places adolescents at special risk (Kipke, Simon, Montgomery, Unger, \& Iverson, 1997; Whitbeck, Hoyt, \& Ackley, 1997a). Runaways not only are at risk from exposure to predators, they also engage in activities on the streets that put them in harm's way. Street survival strategies often depend on various deviant activities that bring runaways into contact with potential victimizers (Hagen \& McCarthy, 1997).

Lifestyle exposure and routine activity theories (see Cohen, Kluegel, \& Land, 1981; Garofalo, 1987; Hindelang, Gottfredson, \& Garofalo, 1978) are helpful in understanding risk on the streets; however, they do not specify the mechanisms that place runaways in such dangerous situations. This research report draws on life course developmental theory (Elder, 1998) to enhance traditional lifestyle exposure explanations of adolescent victimization and revictimization. Based on a sample of more than 900 homeless and runaway adolescents, the study traces the process through which early abuse by caretakers increases the likelihood of deviant behaviors while the adolescents are on their own. In turn, participation in deviant behaviors places the adolescents at risk for street victimization.

Life course developmental theory, particularly the concept of cumulative consequences of deviant behaviors, has been used to explain why some adolescents persist in antisocial behaviors whereas others do not (Caspi \& Bern, 1990; Moffitt, 1997). The perspective suggests negative chains of events develop momentum over time and become progressively more difficult to alter. For example, a progressive drift into deviant behaviors begins to limit prosocial options. Arrest records, drug use, and alcohol problems reduce employability. Early pregnancies diminish options for education and employment.

Negative chains of events set in motion by coercive/abusive caretakers are particularly insidious (Finkelhor \& Asdigian, 1996; Straus \& Gelles, 1990). Early abusive or harsh parenting socializes children aggressively (Patterson, 1982) and initiates patterns of behaviors that place them at increased risk for future harm.

\section{Victimization among Runaway and Homeless Adolescents}

Runaways tend to be victimized on several levels. A substantial proportion of them leave family situations where they have been seriously harmed. Although rates of adolescent-reported abusive family backgrounds vary widely across studies, all indicate significant physical and sexual abuse. Kurtz, Kurtz, and Jarvis (1991) reported 28\% of 2,019 runaways in shelters in eight southeastern states identified themselves as 
having been sexually or physically abused. Janus, Burgess, and McCormack (1987) found that $71.5 \%$ of the male runaways they interviewed reported physical abuse, and 38.2\% reported sexual abuse. About $30 \%$ of Kufeldt and Nimmo's (1987) sample of 474 runaways reported physical abuse. Bridge, Inc., in Boston (Saltonstall, 1984) reported a 65\% physical abuse rate. Only $5 \%$ of their sample "clearly stated there was no abuse in their homes" (p. 78). Silbert and Pines's (1981) study of juvenile and adult street prostitutes reported a $60 \%$ sexual abuse rate. A Los Angeles County shelter/drop-in center study (Pennbridge, Yates, David, \& MacKenzie, 1990) reported a $47 \%$ abuse/neglect rate. According to the National Network of Runaway and Youth Services, $70 \%$ of adolescents in shelters have been physically and/or sexually abused. Cauce and colleagues (1999) reported that of 304 runaway and homeless adolescents interviewed in Seattle, $45 \%$ of the males and $41 \%$ of the females had been physically abused; $19 \%$ of the males and $47 \%$ of the females had been sexually abused.

Leaving home puts the young people at even greater risk of serious victimization. More than 50\% of Kipke et al.'s (1997) sample of Hollywood street youth feared being shot or stabbed, and almost 50\% feared being sexually assaulted or beaten up. About $51 \%$ actually had been beaten up since being on the streets, $45 \%$ had been chased, and $26 \%$ had been shot at. About $19 \%$ had been stabbed while living on the streets, $15 \%$ sexually assaulted, and 7\% wounded by gunfire. Rotheram-Borus, Rosario, and Koopman (1991) reported that in a New York sample of runaways, $20 \%$ were physically assaulted, $20 \%$ sexually assaulted, and $20 \%$ robbed in the 3 months prior to seeking shelter.

\section{Theoretical Background}

Routine activity and lifestyle exposure theorists (Cohen et al., 1981; Garofalo, 1987; Hindelang et al., 1978) have long made the implicit case for similarities between offenders and victims. Specifically, the principle of homogamy suggests that "to the degree that persons share sociodemographic characteristics with potential offenders they are more likely to interact socially with such potential offenders, thus increasing the risk factor of exposure" (Cohen et al., 1981, p. 509; based on Hindelang et al., 1978, pp. 257-259). Running away puts adolescents in a deviant subculture peopled primarily by other homeless and runaway adolescents and others who live most or all of their lives on the streets. Indeed, runaways fulfill nearly all of the risk criteria enumerated in lifestyle exposure theory (Cohen et al., 1981, pp. 507-509). They spend all or much of their time directly on the streets providing maximum exposure to potential victimizers. Runaways congregate in areas of cities that place them in 
the proximity of predators. There is little or no guardianship, other than what is provided by peers, who may be alternately protectors and victimizers in the transient social networks of runaways. Runaways enter an environment where they may be victimized with impunity. Going to the police means reentering spheres of adult control through referrals to shelters, group homes, or even juvenile detention because of their status. Because victimization may often occur in the context of deviant subsistence strategies such as drug dealing, mugging, or survival sex, seeking help may be self-incriminating. Finally, runaways make highly attractive targets, particularly for sexual victimization, because of their youth and vulnerability.

Exposure theories begin with potential victims in high-risk locations, associating with potential victimizers, and engaging in risky behaviors. The theories do not explain how the potential victims come to be at risk. Exposure theories are even less successful at explaining revictimization, except insofar as potential victims remain in risky situations accessible to predators. Life course developmental theory enhances exposure theories by explaining antecedents of adolescent risk and propensity for revictimization. Moffitt (1997) has argued that some adolescents become entrapped in a cumulative progression of deviant behaviors. These developmental trajectories originate early in life and are perpetuated through aggressive/coercive parenting. Parents with difficult children (e.g., those with attention deficit hyperactivity disorder, oppositional defiant, or conduct problems) are often those who are least able to cope effectively with them. Low birth weight, poor nutrition, early pregnancies, and lack of prenatal care are all associated with early developmental and learning problems and are most prevalent among young, often poor mothers. Difficult children elicit inconsistent, often aggressive/coercive parenting. The children are socialized to be aggressive (Patterson, 1982), and these aggressive interactions lead to academic troubles and rejection by conventional peers (Dodge, 1983). Negative chains of events are put into motion that gain momentum across time and become more and more difficult to alter. School failure reduces options, as do alcohol/drug use, early arrests, and early assertion of adult status. As the consequences of negative behaviors accumulate, prosocial options diminish (Caspi \& Bem, 1990).

Running away is a dramatic severance of adult control and prosocial options. Legitimate means of self-support are limited, increasing the likelihood of deviant subsistence strategies (Hagen \& McCarthy, 1997; Whitbeck et al., 1997a). Engaging in deviant subsistence strategies involves affiliation with deviant peers (potential victimizers) and high-risk interactions involving violence (mugging, robberies) or a very high risk of violence (drug dealing, survival sex) (Whitbeck, Hoyt, \& Yoder, 1999). In 
some ways, homeless adolescents are the embodiment of the process of cumulative negative outcomes. Important sources of support have been severed. Antisocial options have begun to outnumber prosocial options.

\section{Hypotheses}

\section{Deviant Subsistence Strategies}

Our hypotheses pertaining to deviant subsistence strategies were based on Whitbeck and colleagues' findings that a history of family abuse increased deviant behaviors among runaway adolescents in three ways. First, runaways with abusive family histories ran away more often and spent more time on their own. Second, runaways with abusive family histories were more likely to affiliate with deviant peers. Third, physically and/or sexually abused runaways were more likely to engage in deviant behaviors (e.g., drug and alcohol use, survival sex, drug dealing) when on their own (Whitbeck \& Hoyt, 1999). Based on these findings, we hypothesized the following:

Hypothesis 1: Runaway adolescents with a history of family abuse will be more likely to engage in sexual and nonsexual deviant subsistence strategies.

Our second hypothesis took into consideration the influence of adolescent characteristics and street behaviors on deviant subsistence strategies employed on the streets.

Hypothesis 2: The age at first run, sexual orientation, drug use on the street, and affiliation with deviant peers are predicted to increase participation in sexual and nonsexual deviant subsistence strategies.

This hypothesis also represents an outcome of cumulative continuity (Caspi \& Bem, 1990). The pattern of life experiences and behaviors that led to precocious independence also eliminated most legitimate means of support (Hagen \& McCarthy, 1997; Whitbeck \& Hoyt, 1999).

One potential source of adolescent resiliency is continued ties to home and positive support from others on the street. There is evidence that such social support decreases participation in deviant behaviors (Whitbeck \& Hoyt, 1999). We therefore hypothesized the following:

Hypothesis 3: Instrumental and emotional support from relatives and from peers on the street will be negatively associated with sexual and nonsexual deviant subsistence strategies. 
Hypotheses Pertaining to Physical and Sexual Victimization

A second set of hypotheses was used to examine the relationship between sexual and nonsexual deviant subsistence strategies and physical and sexual victimization when the adolescents were on their own. Building on factors contributing to risk via deviant subsistence strategies, we hypothesized the following:

Hypothesis 4: Participation in sexual and nonsexual deviant subsistence strategies will increase risk of street victimization even when controlling for family background variables, other risky street behaviors, and support from family or friends.

In summary, we predict that the children who were victimized by caretakers will be those who will engage in more high-risk behaviors in novel situations. Behavioral and interactional characteristics learned in aggressive/abusive situations will place them at greater risk for revictimization when they are on their own.

\section{Method}

\section{Sample}

Two samples of homeless and runaway adolescents were combined for this analysis: 372 adolescents from the Seattle Homeless Youth Project and 602 adolescents from the Midwest Homeless and Runaway Adolescent Project. The investigators on each project collaborated to ensure that the same measures were used on basic variables to provide for replication of findings between Midwest cities and a coastal population center.

Midwest Homeless and Runaway Adolescent Project. During a period of about 18 months from early 1995 through August 1996, 602 adolescents were interviewed by street outreach workers in youth services agencies. The six participating agencies were located in four Midwestern states (Missouri, Iowa, Nebraska, and Kansas) in cities of widely varying populations. Interviews were conducted in outreach vans, restaurants, shelters, transitional living facilities, and drop-in centers as part of regular agency outreach. Interviews lasted about 1/2 hours. Respondents were paid \$15 for participating. Informed consent included a statement explaining the mandatory reporting of child abuse and a statement of our responsibility for obtaining help if the respondent was actively suicidal. Our overall response rate was $93 \%$. Reimbursement rates and a majority of shelter re- 
spondents account for the high adolescent response rates.

We obtained usable interviews for 241 young men and 361 young women. The adolescents ranged in age from 12 years to 22 years. The average age was about 7 months older for young men (16.6 years) than for young women (16 years). Modal categories were 17 years (21\%) for the young men and 16 years for the young women $(25 \%)$. Ages were almost normally distributed with very few falling into the oldest or youngest age brackets.

Although the majority (61\%) of respondents were European American, almost one fourth were African American, with the remainder Hispanic, Native American, or "other." About 5\% of the respondents reported same-sex sexual orientation. Prior to running away, more than one half had lived in large metropolitan areas (more than 100,000 people) or a suburb of a large urban area. Only $7 \%$ of the sample came from very small communities or had lived on farms. Most of the adolescents had been housed the week prior to the interview. Almost one half $(49 \%)$ had spent the previous week in a shelter, $23 \%$ had been living with friends, and $14 \%$ had been with their parents the week prior to running away. Only about $3 \%$ had spent the previous week directly on the streets.

To obtain estimations of social origins, we asked the adolescents about their primary caretakers. Because of the number of caretaker transitions most of these young people have had, respondents were asked to designate the most important adult guardian in their lives, "the adult who cared about you the most, lived with you, and helped raise you as you were growing up." Two thirds (64\%) named their mothers as their primary caretaker, $12 \%$ their fathers, and about $8 \%$ their grandmothers. The remaining $16 \%$ of the caretakers were widely scattered among step-relatives, adoptive parents, and nonrelatives.

According to the adolescents, about $22 \%$ of the primary caretakers had not completed high school, $18 \%$ had completed college or a technical/trade school, and 3\% had an advanced degree. Two thirds of the young people reported that their primary caretakers were employed full-time (66\%). About $12 \%$ were unemployed. There was considerable variation in the occupational categories (Dictionary of Occupational Titles, 1991) of caretakers. Of the parents/caretakers who were employed, $18 \%$ were reported to be professionals or managers; almost $25 \%$ were technicians, administrative support workers, or salespeople; $27 \%$ were service workers; and $15 \%$ were laborers. Almost one half of the adolescents said that their primary caretaker had been "on welfare" at some time when the adolescent was still at home; of these, three fourths $(73 \%)$ reported having received food stamps while living with their primary caretakers. 
Seattle Homeless Youth Project. The Seattle sample consisted of 372 homeless and runaway adolescents interviewed during 1997 and 1998 in shelters and directly on the streets in various locations in the Seattle metropolitan area. Shelter interviews were conducted in various youth services agencies. Street intercept interviews were conducted in restaurants, coffee houses, libraries, or outside if weather permitted. Youths were recruited by direct referrals from shelters and drop-in centers, fliers posted in agencies, and group informational meetings at agencies. Informed consent included statements that the interviewers were mandatory reporters of child abuse and would seek help for the adolescent if he or she were actively suicidal. For the adolescents' protection, a Grant of Confidentiality was obtained through the funding agency. The interview was conducted in two parts on separate days due to length. Each interview lasted about $1 \frac{1 / 2}{2}$ to 2 hours. Respondents were paid $\$ 10$ for each interview day with a $\$ 5$ bonus for completing both sections.

Usable questionnaires were obtained from 203 males and 169 females. The response rate was $95 \%$. The adolescents ranged in age from 12 years to 21 years. The average age was 17.6 years for males and 16.6 years for females. About $53 \%$ of the respondents were European American, $18 \%$ were African American, 19\% were Native American or Alaska Natives, 7\% were Hispanic: and 3\% were Asian Americans. About $31 \%$ of the respondents reported same-sex sexual orientation.

About one third (36\%) of the Seattle adolescents had spent at least part of the previous week in a shelter, $31 \%$ had spent part of the previous week living with a friend, and $6 \%$ had been in their parents' home during the previous week. About $25 \%$ had spent at least one night during the previous week directly on the streets.

Based on adolescents' reports, $10 \%$ of their primary caretakers had not completed high school, $20 \%$ had completed college, and $7.3 \%$ had attended a technical or trade school. About $9 \%$ of primary caretakers had an advanced degree. About two thirds (62\%) of the primary caretakers were employed full-time; $12 \%$ were unemployed. As was the case with the Midwest sample, there was a great deal of variation in the occupational categories of the caretakers (Dictionary of Occupational Titles, 1991). About 26\% were reported to be professionals or managers; $26 \%$ were technicians, administrative support workers, or salespeople; $24 \%$ were service workers; and $12 \%$ were laborers. About $41 \%$ of the adolescents said that their primary caretaker had been on welfare at some time when the adolescent was still at home.

Comparisons of the two samples. There was some evidence of differences between the Seattle and the Midwest samples (Table 1). The Seattle adolescents tended to be older, were more likely to be male, and were 


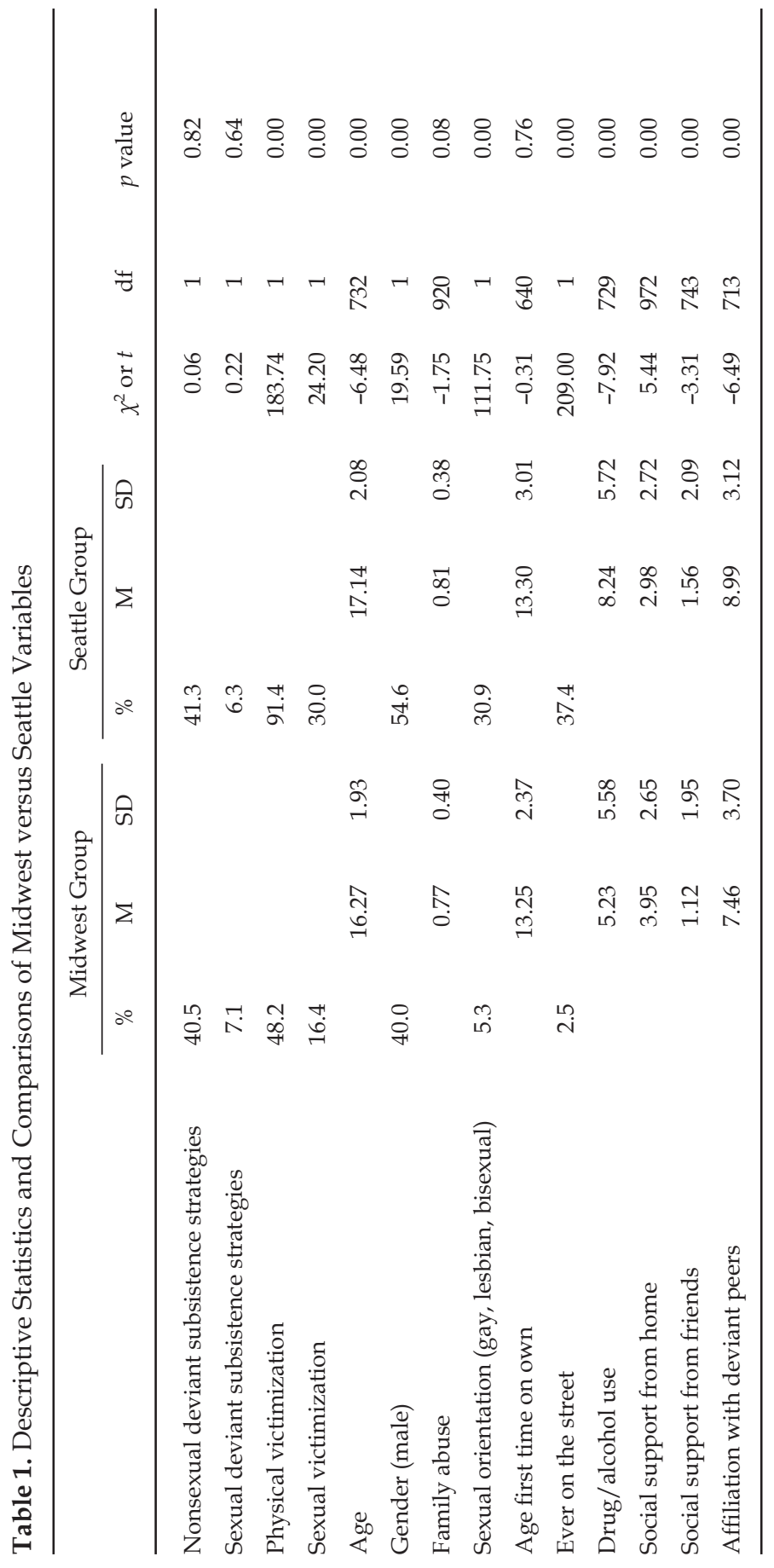


significantly more likely to have been victimized while on their own. They were also more likely to use drugs. Moreover, the Seattle sample had 6 times the proportion of adolescents who self-identified as gay or lesbian in their sexual orientation. We found no significant differences between the two samples regarding participating in deviant subsistence strategies and age at which the youth were first on their own.

There are two possible explanations for the sample differences. The most likely is that they are the result of the higher proportion of Seattle adolescents recruited directly on the streets rather than in youth shelters. More than one third of the Seattle sample had spent time on the streets the week before they were interviewed, compared with less than $3 \%$ of the Midwest sample. Another possible explanation for the sample differences is that Seattle may attract a more mobile and more deviant type of runaway and homeless adolescent due to its location as a magnet city for runaways. Its location along the northwest interstate corridor draws runaways from northern and southern metropolitan areas as well as those "running to the coast" from inland cities.

\section{Measures}

Non-sexual deviant subsistence strategies were measured by dichotomous variables where $0=$ did not engage in at least one of four deviant subsistence strategies and $1=$ engaged in at least one of the four since they had been on their own. The four deviant subsistence strategies were the following: took money from someone, broke in and took money from a store or house, dealt drugs for money, and stole or shoplifted food.

Sexual deviant subsistence strategies were similarly measured. It was a dichotomous variable, where $0=$ did not engage in at least one of four survival sexual behaviors and $1=$ engaged in at least one of the sexual survival behaviors since being on his or her own. The four sexual deviant subsistence strategies were the following: engaged in prostitution for money, traded sex for food, traded sex for food or shelter, and traded sex for money or drugs. The Seattle item asked about trading sex for money, alcohol, or cigarettes; the Midwest questionnaire asked about trading sex for money or drugs.

Family abuse is the sum of nine items that assess the extent to which the adolescents were physically or sexually abused by adult caretakers. The first seven items were based on the Straus and Gelles (1990) Conflict Tactics Scale and involved physical abuse such as: threw something in anger; pushed, shoved, or grabbed in anger; slapped face or head with an open hand; hit with an object; verbally or physically threatened with a 
gun or knife; and wounded or hurt with a gun or knife. The sexual abuse items were: asked you to do something sexual, had you do something sexual, or messed around with you sexually. The items were coded $0=$ never, 1 = once, $2=$ a few times, and $3=$ many times. The scale was constructed by weighting the items to give equal weight to the physical and sexual abuse items and then summing the items. A square-root transformation was taken on the final summed scale to reduce skewness and kurtosis. Cronbach's alpha for the measure was .82 for females and .81 for males.

Sexual orientation was measured with a dichotomous variable where 0 $=$ heterosexual and 1 = gay, lesbian, or bisexual sexual orientation.

Age at first run was a continuous variable that indicated the age in years of the adolescent when he or she first left home without permission.

On the street was a dichotomous variable where $0=$ had not spent at least one night on the street during the past week, and $1=$ spent at least one night on the street in the past week.

Drug and alcohol use assessed alcohol and drug use in the previous year (Midwest survey) or previous 6 months (Seattle survey). Ten items indicated type of substance used: alcohol, marijuana, cocaine or crack, LSD, crank or meth, opiates, speed, tranquilizers, downers, and inhalants. Individual items were coded $0=$ never, $1=$ one/few times, $2=$ monthly, $3=$ weekly, $4=$ daily or almost daily. The items were adjusted to a common time base and summed. Cronbach's alpha for the measure was .83 for females and .84 for males.

Social support from home was assessed by the number of people from home that the adolescent could turn to for instrumental support (lend money, provide food, shelter) or emotional support (people who cared about them).

Social support on the street was a similar count of the number of people on the street to whom the adolescent could turn for instrumental support and emotional support.

Affiliation with deviant peers was measured by the sum of 13 items indicating the delinquent activities of friends on the street: ran away, sold drugs, used drugs, was suspended or expelled from school, dropped out of school, shoplifted, broke in, took things, traded sex for money or drugs, traded sex for food or shelter, was arrested, threatened some- 
one with a weapon, and assaulted someone with a weapon. Individual items were coded $0=$ none of their friends had engaged in this behavior, and 1 = a least one friend had engaged in this behavior. The items were summed to form the scale. Cronbach's alpha was .89 for females and .88 for males.

Physical victimization was assessed with four items indicating whether the adolescents had ever been robbed, beaten up, threatened with a weapon, or assaulted and wounded with a weapon when on their own. The measure was dichotomized so that $0=$ was not victimized while on own, and 1 = victimized at least once while on own.

Sexual victimization was similarly assessed with two items: forced to do sexual things and sexually assaulted or raped. The measure was dichotomized so that $0=$ was not sexually assaulted and $1=$ was sexually assaulted on at least one occasion.

\section{Results}

\section{Physical and/or Sexual Abuse by a Caretaker Adult}

The component measures for the abuse, victimization, and subsistence strategy scales provide some context for the experiences of these youth. The reported rates of physical and sexual abuse were comparable to those found in other large studies of runaways. Two thirds $(62.9 \%)$ of the adolescents reported that before they ran away, their adult caretaker had thrown something at them in anger; $22 \%$ said this had happened many times (Table 2). About $77 \%$ had been pushed, shoved, or grabbed in anger by a caretaker; $69.2 \%$ had been slapped in the face with an open hand, and one third (31.4\%) reported this had happened many times. About $63 \%$ had been hit with an object by an adult caretaker; $35.5 \%$ reported that they had been beaten with fists. Almost one fourth $(23.1 \%)$ reported that they had been threatened with a weapon by an adult caretaker, and $7 \%$ indicated that they had been harmed with a weapon by an adult caretaker. High rates of assault with weapons within families of runaways have been corroborated based on parent reports, although the parents/caretakers indicate that the threats with weapons are more likely to originate from the adolescents than from themselves (see Whitbeck, Hoyt, \& Ackley, 1997b). Regardless of who is reporting, families of runaways report high rates of serous violence between parents and offspring. 
About $23 \%$ of the females reported that an adult caretaker had approached them about sexual activity, as did $11.7 \%$ of the males. For the majority of the adolescents who said that they had been asked to do something sexual, this had occurred more than once. More than one

Table 2. Abuse by an Adult Caretaker Prior to Running Away $(N=974)$

\begin{tabular}{|c|c|c|c|c|}
\hline \multirow[b]{2}{*}{ Variable } & \multirow[b]{2}{*}{ Once } & \multicolumn{2}{|c|}{ Percentage of Total Cases } & \multirow[b]{2}{*}{ Ever } \\
\hline & & Few Times & Many Times & \\
\hline \multicolumn{5}{|c|}{ Threw something } \\
\hline Female & 12.6 & 29.8 & 25.7 & 68.1 \\
\hline Male & 9.9 & 29.3 & 17.6 & 56.8 \\
\hline Total & 11.4 & 29.6 & 22.0 & 62.9 \\
\hline \multicolumn{5}{|l|}{ Pushed } \\
\hline Female & 9.8 & 26.6 & 44.5 & 80.9 \\
\hline Male & 10.4 & 27.9 & 33.3 & 71.6 \\
\hline Total & 10.1 & 27.2 & 39.4 & 76.7 \\
\hline \multicolumn{5}{|l|}{ Slapped } \\
\hline Female & 11.5 & 27.5 & 36.0 & 75.1 \\
\hline Male & 12.4 & 23.9 & 25.9 & 62.2 \\
\hline Total & 11.9 & 25.9 & 31.4 & 69.2 \\
\hline \multicolumn{5}{|c|}{ Hit with object } \\
\hline Female & 8.5 & 18.9 & 38.1 & 65.5 \\
\hline Male & 6.5 & 20.3 & 32.9 & 59.7 \\
\hline Total & 7.6 & 19.5 & 35.7 & 62.8 \\
\hline \multicolumn{5}{|l|}{ Beaten up } \\
\hline Female & 11.7 & 10.9 & 16.4 & 39.1 \\
\hline Male & 8.1 & 11.9 & 11.3 & 31.3 \\
\hline Total & 10.1 & 11.4 & 14.1 & 35.5 \\
\hline \multicolumn{5}{|c|}{ Threatened with a weapon } \\
\hline Female & 12.3 & 7.5 & 4.3 & 24.2 \\
\hline Male & 11.0 & 6.3 & 4.5 & 21.8 \\
\hline Total & 11.7 & 7.0 & 4.4 & 23.1 \\
\hline \multicolumn{5}{|c|}{ Wounded with a weapon } \\
\hline Female & 4.5 & 0.9 & 1.1 & 6.6 \\
\hline Male & 4.3 & 2.7 & 0.5 & 7.4 \\
\hline Total & 4.4 & 1.7 & 0.8 & 7.0 \\
\hline \multicolumn{5}{|c|}{ Asked to have sex } \\
\hline Female & 6.4 & 7.4 & 9.2 & 23.0 \\
\hline Male & 4.5 & 4.1 & 3.2 & 11.7 \\
\hline Total & 5.5 & 5.9 & 6.5 & 17.9 \\
\hline \multicolumn{5}{|c|}{ Forced to have sex } \\
\hline Female & 8.3 & 8.9 & 10.2 & 27.4 \\
\hline Male & 2.9 & 3.2 & 3.2 & 9.2 \\
\hline Total & 5.9 & 6.3 & 7.0 & 19.1 \\
\hline
\end{tabular}


fourth $(27.4 \%)$ of the females reported that an adult caretaker had abused them sexually. Of these, $19 \%$ had been molested on more than one occasion. About $9 \%$ of the males had been sexually abused.

Nonsexual and sexual deviant subsistence strategies. The adolescents engaged in a number of sexual and nonsexual deviant subsistence strategies (Table 3). About $22 \%$ of the males had robbed someone, and $16 \%$ had been involved in a burglary. Almost one fourth of males and females had stolen or shoplifted food. About $29 \%$ of the males and $15 \%$ of the females had dealt drugs. As is the case in many studies of runaways, very few reported prostituting themselves or engaging in survival sex. The sexual relationships of runaways are often transitory and in the context of group behaviors. Although an outsider may view the sexual relationship as one of exchange (e.g., sex for drugs or sex for a place to stay), the adolescents may view it in the context of a relationship or an early relationship. That is, "I met someone, we hung out, got high at someone's place, and had sex." More males (3.4\%) than females $(2.5 \%)$ reported prostituting themselves for money. About the same percentages of males and females indicated that they had traded sex for money or drugs ( $4.7 \%$ females; $3.8 \%$ males) or had traded sex for food or shelter ( $4.2 \%$ females; $4.7 \%$ males).

\section{Victimization Rates}

Rates of reported victimization were very high (Table 4). One half $(49.5 \%)$ of the adolescent males reported that they had been robbed since being on their own, as had one third of the females (35.8\%). Similar numbers had been beaten up while on their own ( $47.3 \%$ males; $30.8 \%$ females). More than one half of the males (54.3\%) and about one third $(30.4 \%)$ of the females reported that they had been threatened with a weapon. Of these, $34.6 \%$ of the males and $16.6 \%$ of the females had been threatened with a weapon on more than one occasion. Almost one third of the males $(29.7 \%)$ had been assaulted or wounded with a weapon, as had $12.6 \%$ of the females. About $25 \%$ of the females and $9.2 \%$ of the males reported that they had been "forced to do sexual things" since being on their own. About $23 \%$ of the females said they had been sexually assaulted or raped since being on their own, as did $7.2 \%$ of the males.

\section{Predicting Deviant Subsistence Strategies}

Bivariate correlations (Table 5) between the variables included in the regression models indicate that family abuse and almost all of the street 
variables were correlated with physical and sexual victimization. As problem behavior theory would suggest, almost all of the nonconventional behaviors (e.g., sexual and nonsexual deviant subsistence strategies, age at first run, ever on street, drug/alcohol use) were intercorrelated at the bivariate level. A history of family abuse was correlated with all of the variables with the exception of having ever spent time directly on the streets.

Separate logistic regression models were used to investigate factors leading to nonsexual and sexual deviant behaviors on the streets. The first model included only control variables of age, gender, and family abuse. In Model 2, the street variables were added. Gender interactions were checked with each of the variables in the model. Significant gender interactions were then included in the models.

Table 3. Deviant Subsistence Strategies

\begin{tabular}{lc}
\hline Variable & Percentage of Total Cases \\
\hline Took money from someone & 11.9 \\
Female & 21.6 \\
Male & 16.3 \\
Total & \\
Broke in and took something & 5.5 \\
Female & 16.4 \\
Male & 10.5 \\
Total & \\
Stealing or shoplifting food & 18.9 \\
Female & 28.6 \\
Male & 23.3 \\
Total & 15.1 \\
Drug dealing for money & 28.8 \\
Female & 21.4 \\
Male & \\
Total & 2.5 \\
Prostitution for money & 3.4 \\
Female & 2.9 \\
Male & \\
Total & 4.7 \\
Ever traded sex for money or drugs & 3.8 \\
Female & 4.3 \\
Male & \\
Total & 4.2 \\
Ever traded sex for food or shelter & 4.7 \\
Female & 4.4 \\
Male & \\
Total & \\
\hline
\end{tabular}


Nonsexual deviant subsistence strategies. In Model 1 (Table 6), a history of family abuse increased the likelihood of engaging in nonsexual deviant subsistence strategies (e.g., robbery, burglary, shoplifting, and dealing drugs) twofold, $\operatorname{Exp}(B)=2.1$. When controlling only for family abuse, males were 2.5 times more likely to be involved in nonsexual deviant subsistence strategies than were females.

When the street variables were added to the model, family abuse became nonsignificant. Gender, however, continued to exert a strong effect. Males were more than 2.5 times more likely to engage in nonsexual deviant subsistence strategies than were females. The only other statistically significant predictors of nonsexual deviant subsistence strategies in the full model were drug and alcohol use while the adolescents were on their own and affiliation with deviant peers.

Table 4. Physical and Sexual Victimization

\begin{tabular}{|c|c|c|c|c|}
\hline \multirow[b]{2}{*}{ Variable } & \multicolumn{4}{|c|}{ Percentage of Total Cases } \\
\hline & Once & Few Times & Many Times & Ever \\
\hline \multicolumn{5}{|l|}{ Robbed } \\
\hline Female & 12.6 & 13.2 & 10.0 & 35.8 \\
\hline Male & 15.3 & 20.0 & 14.2 & 49.5 \\
\hline Total & 13.9 & 16.3 & 11.9 & 42.1 \\
\hline \multicolumn{5}{|l|}{ Beaten up } \\
\hline Female & 11.7 & 12.3 & 6.8 & 30.8 \\
\hline Male & 14.2 & 20.3 & 12.8 & 47.3 \\
\hline Total & 12.8 & 15.9 & 9.5 & 38.3 \\
\hline \multicolumn{5}{|c|}{ Threatened with a weapon } \\
\hline Female & 13.8 & 11.7 & 4.9 & 30.4 \\
\hline Male & 19.6 & 19.1 & 15.5 & 54.3 \\
\hline Total & 16.4 & 15.1 & 9.8 & 41.3 \\
\hline \multicolumn{5}{|c|}{ Assaulted with a weapon } \\
\hline Female & 7.5 & 4.2 & 0.9 & 12.6 \\
\hline Male & 14.0 & 10.8 & 5.0 & 29.7 \\
\hline Total & 10.5 & 7.2 & 2.8 & 20.4 \\
\hline \multicolumn{5}{|c|}{ Forced to have sex } \\
\hline Female & 11.7 & 10.0 & 3.6 & 25.3 \\
\hline Male & 6.3 & 1.6 & 1.4 & 9.2 \\
\hline Total & 9.2 & 6.2 & 2.6 & 18.0 \\
\hline \multicolumn{5}{|c|}{ Sexual assault/rape } \\
\hline Female & 13.0 & 7.0 & 2.8 & 22.8 \\
\hline Male & 5.0 & 1.1 & 1.1 & 7.2 \\
\hline Total & 9.3 & 4.3 & 2.1 & 15.7 \\
\hline
\end{tabular}


Sexual deviant subsistence strategies. For sexual deviant subsistence strategies (Table 6), age of adolescent was significant in Model 1. The older the adolescent, the more likely he or she had engaged in survival sex. Gender was nonsignificant in Model 1. Family abuse was statistically significant and increased the likelihood adolescents would engage in survival sex almost 8 times, $\operatorname{Exp}(B)=7.7$, when controlling only for age and gender of adolescent.

In the full model, age became nonsignificant, and gender attained significance. When street variables were added into the model, adolescent females were 20 times more likely to engage in survival sex than were adolescent males. Family abuse remained significant and increased the probability of survival sex more than 4 times, $\operatorname{Exp}(B)=4.5$. Adolescents' sexual orientation was also significant. Runaways with same-sex sexual orientation were almost 3 times, $\operatorname{Exp}(B)=2.8$, more likely to engage in survival sex than those with heterosexual orientations. These findings place the initial lack of a correlation between gender and sexual deviant subsistence strategies in perspective. Two groups have elevated risk profiles: heterosexual females and homosexual males. Prior to controlling for sexual orientation, these patterns counterbalance each other in the bivariate association between gender and sexual deviant subsistence strategies.

Drug and alcohol use were positively related to engaging in survival sex, as was affiliation with deviant peers when adolescents were on their own. The perception of continued social support from home (e.g., relatives who provided instrumental and emotional support) was negatively associated with sexual survival strategies, decreasing the likelihood of the behaviors by $13 \%, \operatorname{Exp}(B)=.87$. The interaction between gender and age at first run was statistically significant and remained significant in the full model. The likelihood of engaging in survival sex increased as age at first run increased for males. Conversely, the older the adolescent female was at first run, the less likely she would engage in sexual survival strategies.

In Model 3, engaging in nonsexual deviant subsistence strategies was introduced. Participation in one type of deviant subsistence strategy strongly predicted participation in the other. Adolescents who engaged in nonsexual deviant subsistence strategies were almost 4 times, $\operatorname{Exp}(B)=3.7$, more likely to also engage in sexual deviant subsistence strategies than were those who did not. Drug and alcohol use remained significant in Model 3; however, the sign changed direction when nonsexual deviant subsistence strategies were introduced. Perceived social support from home became nonsignificant, as did affiliation with deviant peers. The gender interaction with age at first run remained significant. 


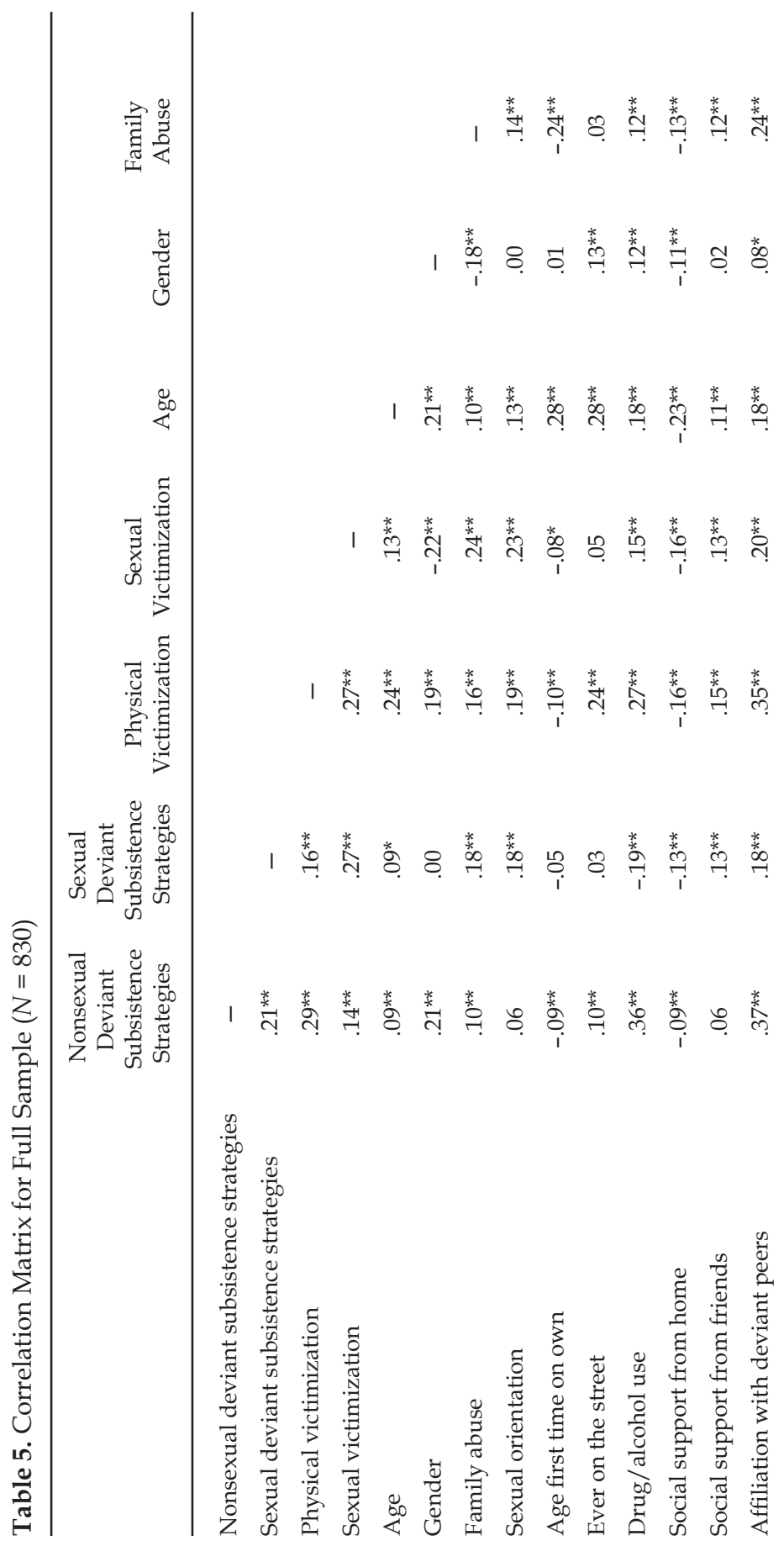




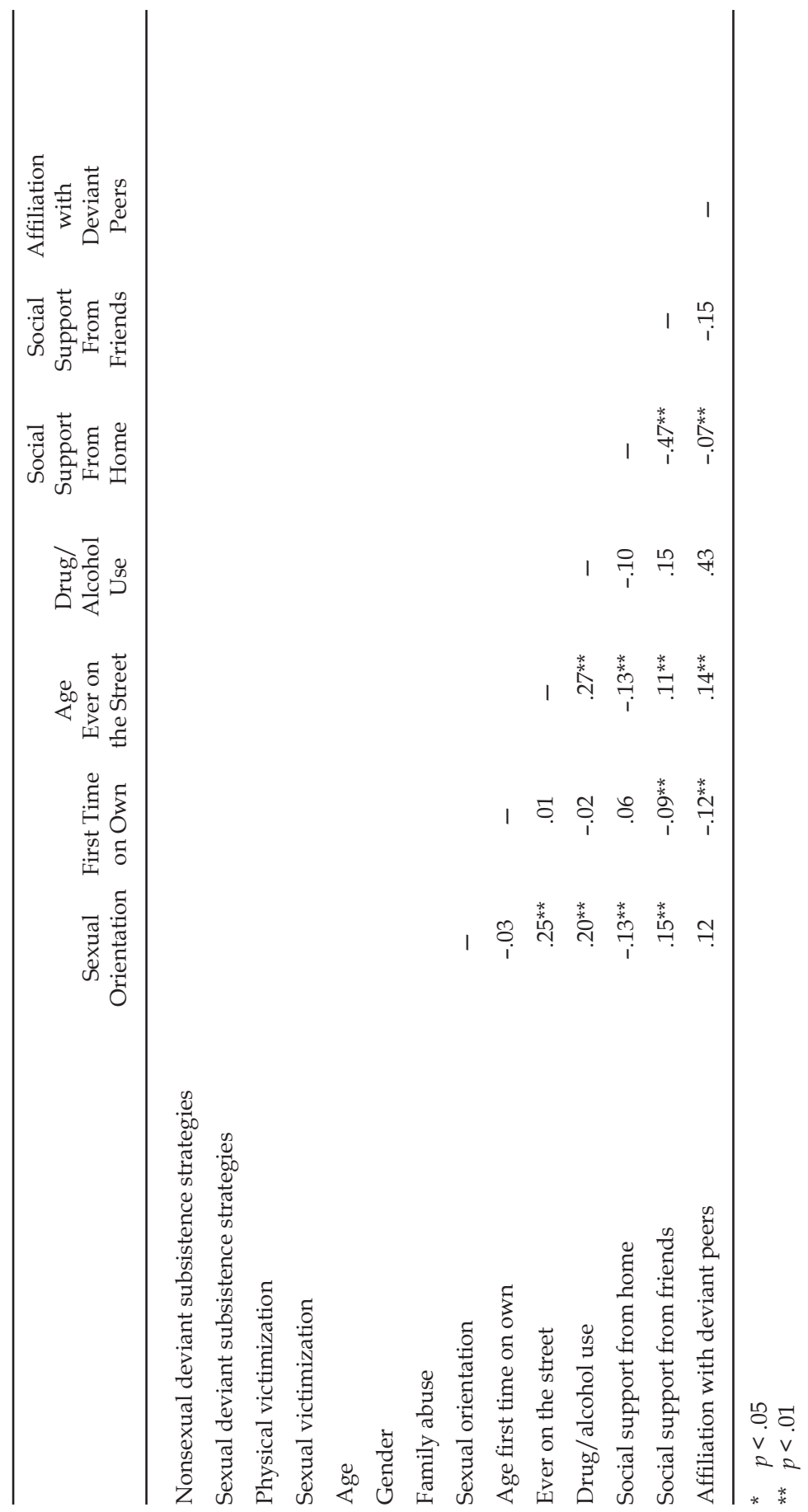




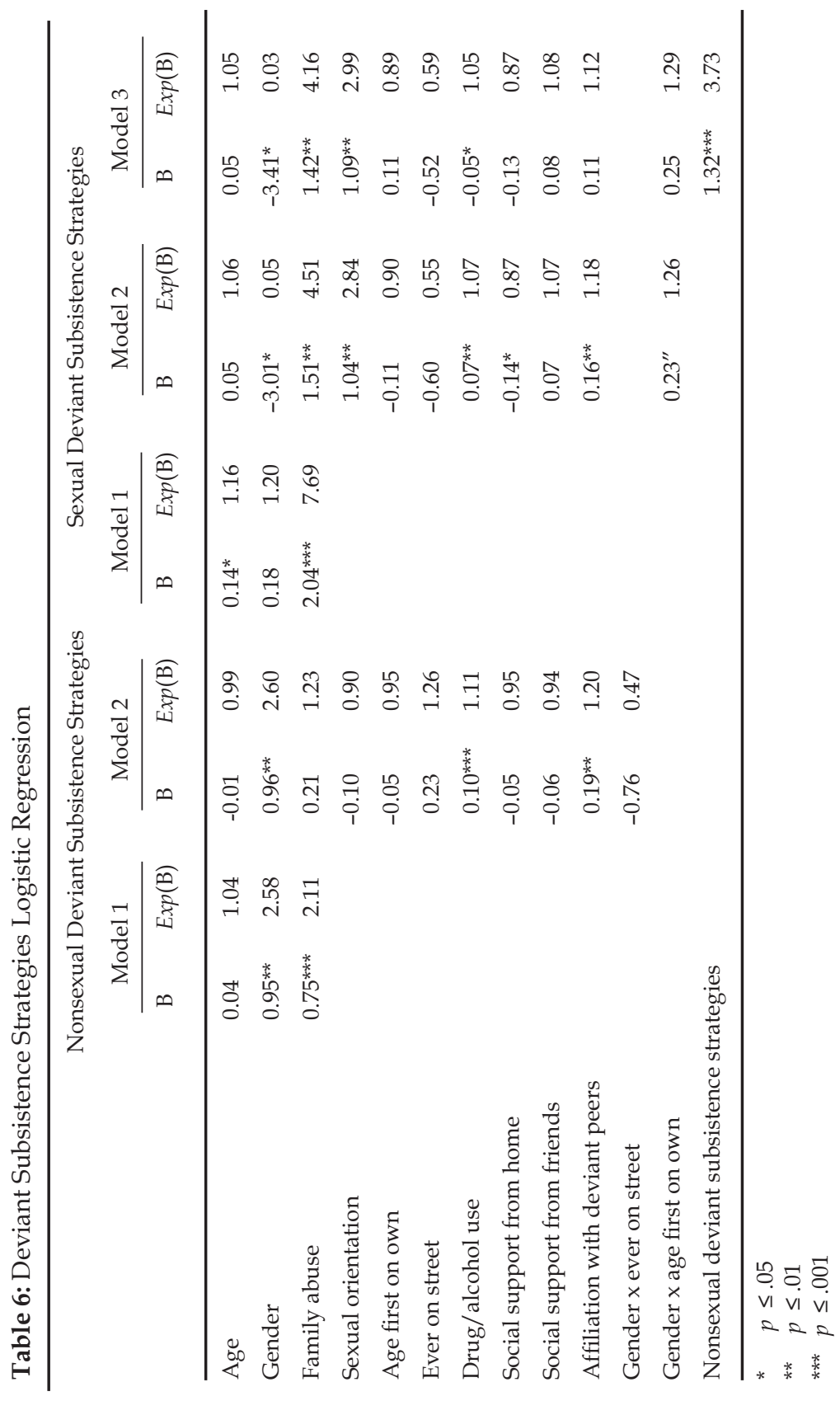




\section{Deviant Subsistence Strategies and Physical and Sexual Victimization}

Similar logistic regression models were run on the physical and sexual victimization variables. In each of the regressions, Model 1 included only control variables age and gender and our measure of physical and sexual abuse. In Model 2, the street variables were added into the equation. In Model 3, nonsexual and sexual deviant subsistence strategies were added to the equation.

Physical victimization. In Model 1 (Table 7), with control variables age and gender, a history of abuse by an adult caretaker prior to running away increased the likelihood of physical victimization when the adolescents were on their own almost 3 times, $\operatorname{Exp}(B)=2.8$. Age was also statistically significant, indicating that risk of physical victimization when adolescents were on their own increased with the age of the adolescent. With only age and family abuse in the model, gender was highly significant, indicating that adolescent males were more than 2 times more likely to be physically victimized when on the streets than were adolescent females, $\operatorname{Exp}(B)=2.4$.

When the street variables were added into the model, age, gender, and family abuse remained statistically significant. Adolescent males remained more than twice, $\operatorname{Exp}(B)=2.6$, as likely to be victimized compared with females, even when controlling for street behaviors. Abuse by an adult caretaker prior to running away increased the likelihood of physical victimization 1.7 times. Age at first run was negatively associated with physical victimization, indicating that the earlier the adolescent left home the first time, the more likely he or she would experience physical victimization when on the streets. Ever having spent at least one night directly on the streets increased the likelihood of physical victimization more than 4 times, $\operatorname{Exp}(B)=4.3$. Drug and alcohol use remained marginally significant $(p=.06)$. Affiliation with deviant peers was positively associated with physical victimization. Of the three interactions that were significantly associated with physical victimization when checked in individual regression models, none remained significant when introduced in Model 2.

In the third model, nonsexual and sexual deviant subsistence strategies were added to the equation. Although age and gender remained in the model, family abuse dropped to marginal significance $(p=.06)$. Risk of physical victimization remained twice as likely for males compared with females. Age at first run also remained in the model, as did having ever spent time directly on the streets. Spending time on the streets increased risk of victimization almost fivefold, $\operatorname{Exp}(B)=4$.6. Affiliation with 
deviant peers remained in the model. Participation in nonsexual deviant subsistence strategies increased the likelihood of physical victimization 2 times, $\operatorname{Exp}(B)=2.0$. Sexual deviant subsistence strategies approached but did not attain statistical significance $(p=.08)$.

Sexual victimization. All of the variables in Model 1 were significantly associated with sexual victimization (Table 8). The adolescents were more likely to be sexually victimized when on the streets if they were older, were female, and had a history of physical and/or sexual abuse by an adult caretaker. Having a background of abuse within the family increased the likelihood of sexual victimization when adolescents were on their own almost fourfold, $\operatorname{Exp}(B)=3.8$, when controlling only for age

Table 7. Physical Victimization Logistic Regression Models

\begin{tabular}{|c|c|c|c|c|c|c|}
\hline & \multicolumn{2}{|c|}{ Model 1} & \multicolumn{2}{|c|}{ Model 2} & \multicolumn{2}{|c|}{ Model 3} \\
\hline & B & $\operatorname{Exp}(\mathrm{B})$ & B & $\operatorname{Exp}(\mathrm{B})$ & $\mathrm{B}$ & $\operatorname{Exp}(\mathrm{B})$ \\
\hline Age & $0.22^{* * *}$ & 1.24 & $0.17^{* * *}$ & 1.19 & 0.17 & 1.19 \\
\hline Gender & $0.87^{* * *}$ & 2.37 & $0.96^{*}$ & 2.61 & $0.86^{*}$ & 2.37 \\
\hline \multicolumn{3}{|l|}{ Family abuse } & $0.50^{*}$ & 1.65 & 0.44 & 1.55 \\
\hline \multicolumn{3}{|l|}{ Sexual orientation } & 0.41 & 1.51 & 0.38 & 1.46 \\
\hline \multicolumn{3}{|l|}{ Age first on own } & $-0.10^{*}$ & 0.91 & $-0.09^{*}$ & 0.92 \\
\hline \multicolumn{3}{|l|}{ Ever on street } & $1.46^{* * *}$ & 4.31 & $1.53^{* * *}$ & 4.61 \\
\hline \multicolumn{3}{|l|}{ Drug/alcohol use } & 0.04 & 1.04 & 0.02 & 1.02 \\
\hline \multicolumn{3}{|c|}{ Social support from home } & 0.02 & 1.02 & 0.03 & 1.04 \\
\hline \multicolumn{3}{|c|}{ Social support from friends } & 0.00 & 0.94 & 0.00 & 1.00 \\
\hline \multicolumn{3}{|c|}{ Affiliation with deviant peers } & $0.15^{* * *}$ & 1.17 & $0.13^{* * *}$ & 1.14 \\
\hline \multicolumn{3}{|c|}{ Gender $x$ sexual orientation } & 1.56 & 4.74 & 1.58 & 4.84 \\
\hline \multicolumn{3}{|c|}{ Gender $x$ social support from home } & -0.12 & 0.89 & -0.12 & 0.89 \\
\hline \multicolumn{3}{|c|}{ Gender x social support from friends } & 0.14 & 1.15 & 0.16 & 1.17 \\
\hline \multicolumn{5}{|c|}{ Nonsexual deviant subsistence strategies } & $0.67^{* * *}$ & 1.95 \\
\hline \multicolumn{5}{|c|}{ Sexual deviant subsistence strategies } & 0.92 & 2.50 \\
\hline
\end{tabular}


and gender of runaway. Adolescent females were almost 4 times more likely to be sexually victimized than males.

All three of the variables that were statistically significant in Model 1 remained significant in Model 2. The impact of family abuse dropped, from increasing the probability of sexual victimization 4 times to 2 times, $\operatorname{Exp}(B)=2.3$. However, when the street variables were added to the model, the odds of females being sexually victimized increased from about 4 times to more than 5 times, $\operatorname{Exp}(B)=0.17$. Drug and alcohol use was significantly associated with sexual victimization. Perceived social support from family decreased the likelihood of sexual victimization on the streets by $12 \%, \operatorname{Exp}(B)=0.88$. Deviant peer affiliations were positively associated with sexual victimization. Two gender interactions were statistically significant in Model 2. A gender by sexual orientation interaction indicated that the increase in risk of sexual victimization for males with same-sex sexual orientation was much greater than for females with

Table 8. Sexual Victimization Logistic Regression Models

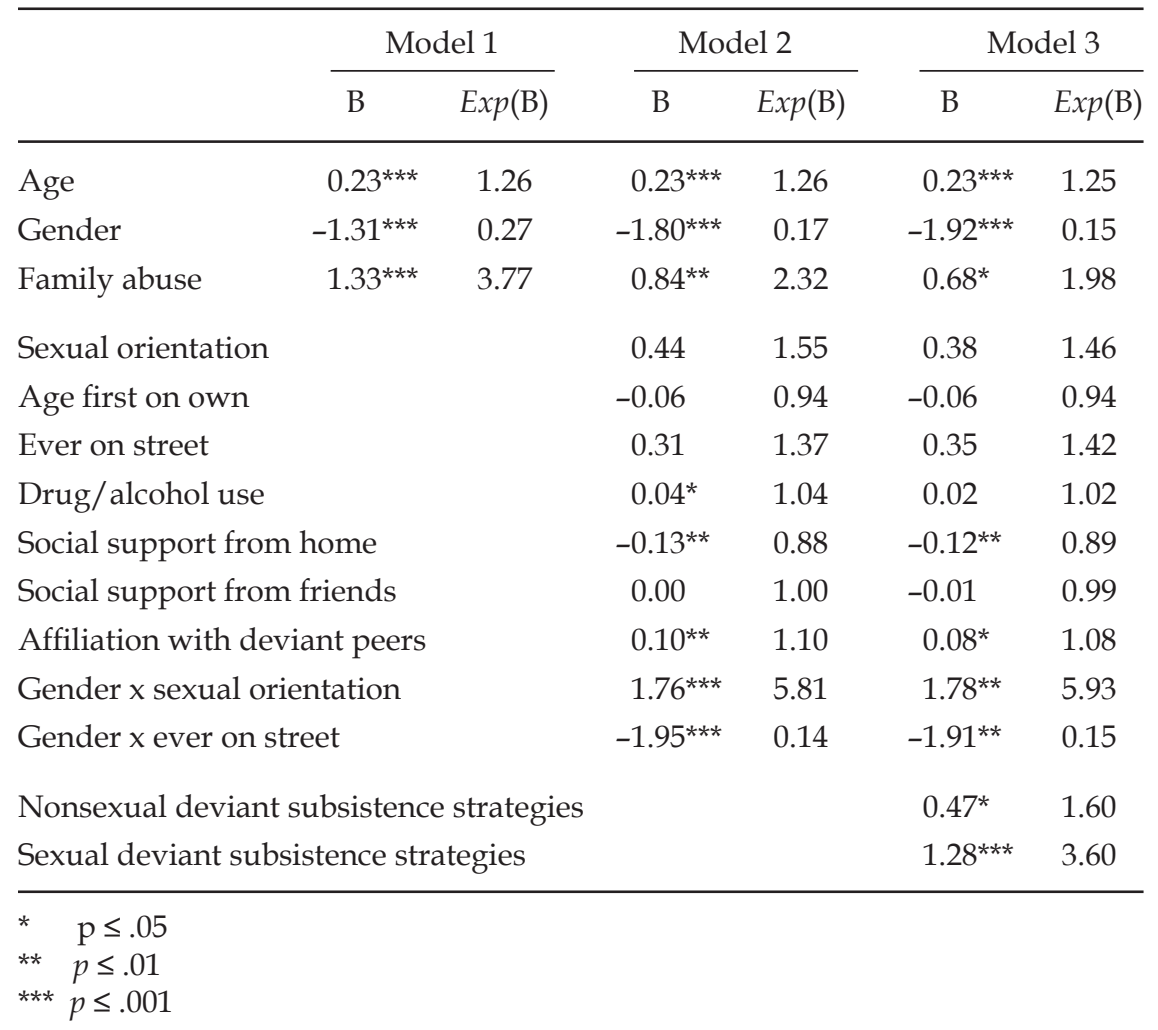


same-sex sexual orientation. Risk for gay and bisexual male runaways approaches that of heterosexual females. The gender by ever having spent time directly on the street interaction indicated that having ever spent time directly on the street increased risk of sexual victimization for females but not for males.

The two measures of deviant subsistence strategies were added to the equation in Model 3. With the exception of drug and alcohol use, which became nonsignificant, the variables that were significant in Model 2 were relatively stable in Model 3. The odds that females would be sexually victimized increased with the addition of the deviant subsistence variables from 5 to almost 7 times. Both nonsexual deviant subsistence strategies and sexual deviant subsistence strategies were significantly associated with sexual victimization on the streets. Engaging in nonsexual deviant subsistence strategies increased the likelihood of sexual victimization 1.6 times. Sexual deviant subsistence strategies (survival sex) increased risk of sexual victimization nearly 4 times, $\operatorname{Exp}(B)=3.6$. The interactions that were statistically significant in Model 2 remained significant in the full model.

\section{Discussion}

\section{Deviant Subsistence Strategies}

Histories of caretaker physical and/or sexual abuse had strong direct effects on deviant subsistence strategies when controlling only for gender and age of adolescents. When behavioral variables were added to the equation, family abuse lost statistical significance in models for nonsexual deviant subsistence strategies but remained significant in the models for sexual deviant subsistence strategies. Bivariate correlations between family abuse and the street variables indicate that problem behaviors were associated with a history of caretaker maltreatment. In the multivariate analysis, street experiences mediated the effects of early maltreatment on nonsexual deviant behaviors (see Baron \& Kenny, 1986, for a discussion on criteria for mediation of effects). Family factors played a more persistent role in explaining later survival sex. Physical and sexual maltreatment in families of origin increased the likelihood of engaging in survival sex more than 4 times, even when controlling for street behaviors and nonsexual deviant subsistence strategies.

Runaways' participation in specific kinds of deviant subsistence strategies was gender related. Adolescent males were almost 3 times more likely than females to engage in nonsexual deviant subsistence strategies 
(e.g., robbing someone, burglarizing, dealing drugs, stealing/shoplifting food). Females, on the other hand, were about 20 times more likely to engage in sexual deviant subsistence strategies (survival sex) than were males. Engaging in sexual deviant subsistence strategies was also related to sexual orientation. Adolescents of same-sex sexual orientation were 3 times more likely to engage in survival sex than were their heterosexual counterparts. In general, when sexual attractiveness to males was a resource for runaway and homeless adolescents, it was more likely to be relied on as a way to get by on the streets.

Adolescents who were involved in nonsexual deviant subsistence strategies were almost 4 times more likely also to engage in sexual deviant subsistence strategies (i.e., survival sex). Besides gender, the best predictors of nonsexual deviant subsistence strategies on the streets were hanging out with deviant peers and using alcohol or drugs.

\section{Victimization}

A history of family abuse had independent effects on the probability of sexual victimization (Table 8) but became nonsignificant in the final model for physical victimization (Table 7). The risk of being sexually victimized when the adolescents were on their own doubled for adolescents with histories of physical and sexual abuse by a caretaker.

As with deviant subsistence strategies, gender was a strong determinant of victimization patterns among runaway adolescents. The adolescent males were more than 2 times more likely to be physically victimized than were females. Females were more than 6 times more likely to be sexually victimized than were males. Moreover, gender interacted with sexual orientation such that adolescent males with same-sex sexual orientation were more likely to experience sexual victimization when on their own than were females with same-sex sexual orientation. Same-sex sexual orientation among young men placed them at about the same level of risk for sexual victimization as the young women. Gender also interacted with the adolescents' having ever been on the street. Spending time directly on the street greatly increased risk for both adolescent males and females; however, adolescent females who had spent at least one night on the street were more at risk for sexual victimization than were their male counterparts.

Street time was a particularly forceful variable. Having spent at least one night directly on the streets increased risk of physical victimization nearly fivefold. Engaging in deviant behaviors while on the street was also a powerful predictor of victimization. Participation in nonsexual deviant subsistence strategies doubled the risk of physical victimization and almost 
doubled the risk of sexual victimization. Sexual deviant subsistence strategies increased the likelihood of sexual victimization almost fourfold.

\section{Conclusions}

Theoretically linking lifestyle exposure and life course theories enhances explanations of victimization among homeless and runaway young people. Life course development history helps to explain the origins of their risky behaviors; lifestyle/exposure theories help to explain the consequences of their behaviors. A history of maltreatment in the family significantly contributed to deviant behaviors and victimization prior to adding street variables to our regression models. The street variables mediated the impact of family abuse on nonsexual deviant behaviors and physical victimization (Baron \& Kenny, 1986), but main effects remained significant for sexual deviance and sexual victimization. From a lifestyle exposure/routine activities perspective, proximity to risk and deviant behaviors increased the likelihood of victimization. Even controlling for other high-risk environmental and behavioral factors, engaging in deviant subsistence strategies doubled and even tripled risk of victimization among runaway and homeless adolescents.

This research with a special population of adolescents addressed all three of the factors raised by Sampson and Lauritsen regarding personal victimization and adolescents: offending, deviant lifestyles, and ecological proximity to crime (Lauritsen et al., 1991; Sampson \& Lauritsen, 1990). Ecological proximity variables (e.g., being on the street) increased the likelihood of physical victimization 5 times and interacted with gender to indicate increased risk of sexual victimization of young women. Affiliation with deviant peers consistently contributed to both deviant behaviors and victimization. Participation in nonsexual deviant subsistence strategies contributed to likelihood of physical victimization; engaging in either nonsexual or sexual deviant subsistence strategies increased risk for sexual victimization.

Our findings indicate that victimization among this high-risk group of adolescents depends not only on where they are but also on what they do. All runaways are at increased risk for victimization because they lack guardianship and typically end up in dangerous locales. However, multiple behavioral factors increase risk of serious harm once runaways are on their own. Exposure theories suggest that runaways will be almost certain to associate with peers who are likely to be engaged in delinquent behaviors. Life course theory explains why runaways drift into deviant peer groups. Second, adolescents on their own have very few legitimate means of independent support. Exposure theories explain risk factors as- 
sociated with participation in deviant behaviors. Life course theory helps us understand the propensity to engage in high-risk subsistence strategies and, via cumulative continuity (Caspi \& Bem, 1990), the necessity of doing so. Prosocial options for the most part have progressively diminished over time.

Understanding risk among runaway and homeless adolescents involves understanding the dangers associated with a unique adolescent environment as well as the adolescents' own propensity for dangerous interactions and behaviors. The latter is the result of cumulative developmental processes that have resulted in precocious independence (Whitbeck \& Hoyt, 1999). Runaways are in double jeopardy for victimization. Many have been victimized by caretakers. They leave, only to find that their interactive skills and behaviors place them at great risk for serious victimization when on their own.

\section{Some Practical Implications}

Our findings have important implications for practitioners. The first is obvious but too often overlooked as an intervention priority: Homeless and runaway adolescents need safe places. The most immediate need is protection from further harm. However, our findings also suggest that those most in harm's way may be those who will be most difficult to engage. In terms of intervention, the least accessible adolescents, because of their involvement in deviant subsistence strategies, are also those most likely to be the most seriously victimized and at the greatest risk for revictimization. Protecting these adolescents from further harm and its psychological consequences presents significant but not insurmountable problems. The most important first step is understanding that these adolescents are no longer children. Their "too early" adult behaviors have made them precocious adults, and they will resist any attempt to undermine this status.

Second, criminal justice systems that deal with runaway and homeless adolescents tend to view them primarily in terms of their externalizing behaviors and illegal activities (Hagen \& McCarthy, 1997). This is certainly the case in their relations with police (Whitbeck \& Hoyt, 1999). However, although they are public nuisances, homeless and runaway adolescents are also the most severely victimized adolescent population in our society. Programs must be put in place that are careful not to perpetuate this victimization chain through revictimization from adult authority figures. This means eliminating police harassment and police abuse of homeless adolescents (Whitbeck \& Hoyt, 1999). It also means policies that focus on treatment-oriented approaches rather than criminalizing of runaway behaviors. 


\section{References}

Baron, R. M., \& Kenny, D. A. (1986). The moderator-mediator variable distinction in social psychological research: Conceptual, strategic, and statistical considerations. Journal of Personality and Social Psychology, 51, 1173-1182.

Caspi, A., \& Bem, D. J. (1990). Personality continuity and change across the life course. In L. Pervin (ed.), Handbook of Personality Theory and Research (pp. 549575). New York: Guilford.

Cauce, A. M., Paradise, M., Embry, L., Morgan, C., Lohr, Y., Theofeils, J., Moore, E., \& Wagner, V. (1999). Homeless youth in Seattle: Youth characteristics, mental health needs, and intensive case management. In K. Kutash, A. Duchnowski, \& M. Epstein (eds.). Community- based Programming for Children with Serious Emotional Disturbances: Research and Evaluation. Tampa: University of South Florida Press.

Cohen, L. E., Kluegel, J. E., \& Land, K. C. (1981). Social inequality and predatory criminal victimization: An exposition and test of a formal theory. American Sociological Review, 46, 505-524.

Dictionary of Occupational Titles (4th ed.). (1991). Washington, DC: U.S. Employment Service.

Dodge, K. (1983). Behavioral antecedents of peer social status. Child Development. 53, 890-904.

Elder, G. (1998). The life course as developmental theory. Child Development, 69, $1-12$.

Finkelhor, D., \& Asdigian, N. L. (1996). Risk factors for youth victimization: Beyond a lifestyle/routine activities theory approach. Violence and Victims, 11, 3-19.

Garofalo, J. (1987). Reassessing the lifestyle model of criminal victimization. In M. Gottfredson \& T. Hirschi (eds.), Positive Criminology (pp. 23-42). Newbury Park, CA: Sage.

Hagen, J., \& McCarthy, B. (1997). Mean Streets: Youth Crime and Homelessness. Cambridge, UK: Cambridge University Press.

Hindelang, M. S., Gottfredson, M., \& Garofalo, J. (1978). Victims of Personal Crime. Cambridge, MA: Ballinger.

Janus, M.-D., Burgess, A. W., \& McCormack, A. (1987). Histories of sexual abuse in adolescent male runaways. Adolescence, 22, 405-417.

Jensen, G. F., \& Brownfield, D. (1986). Gender, lifestyles, and victimization: Beyond routine activity. Violence and Victims, 1, 85-99.

Jessor, R., \& Jessor, S. L. (1977). Problem Behavior and Psychosocial Development. New York: Academic Press.

Kipke, M. D., Simon, T. R., Montgomery, S. B., Unger, J . B., \& Iverson, E. F. (1997). Homeless youth and their exposure to and involvement in violence while living on the streets. Journal of Adolescent Health, 20, 360-367.

Kufeldt, K., \& Nimmo, M. (1987). Youth on the street: Abuse neglect in the eighties. Child Abuse and Neglect, 11, 531-543. 
Kurtz, P. D., Kurtz, G. L., \& Jarvis, S. V. (1991). Problems of maltreated runaway youth. Adolescence, 26, 544-555.

Lauritsen, J. L., Sampson, R. J., \& Laub, J. H. (1991). The link between offending and victimization among adolescents. Criminology, 29, 265-291.

Moffitt, T. E. (1997). Adolescent-limited and life-course-persistent offending: A complementary pair of developmental theories. In T. Thornberry (ed.), Developmental Theories of Crime and Delinquency (pp. 11-54). New Brunswick, NJ: Transaction.

Patterson, G. R. (1982). Coercive Family Process. Eugene, OR: Castilia.

Pennbridge, J., Yates. G. L., David, T. G., \& MacKenzie, R. G. (1990). Runaway and homeless youth in Los Angeles County, California. Journal of Adolescent Health Care, 11, 159-165.

Rotheram-Borus, M. J., Rosario, M., \& Koopman, C. (1991). Minority youth at high risk: Gay males and runaways. In S. Gore \& M. Colton (eds.). Adolescent Stress: Courses and Consequences (pp. 181-200). New York: Aldine de Gruyter.

Saltonstall, M. (1984). Street Youth and Runaways on the Streets of Boston: One Agency's Response. Boston: The Bridge, Inc.

Sampson, R. J., \& Lauritsen, J. L. (1990). Deviant lifestyles, proximity to crime, and the offender-victim link in personal violence. Journal of Research on Crime and Delinquency, 27, 110-139.

Silbert, M., \& Pines, A. (1981). Sexual child abuse as an antecedent to prostitution. Child Abuse and Neglect, 5, 407-411.

Straus, M. A., \& Gelles, R. J. (1990). Physical Violence in American Families. New Brunswick, NJ: Transaction.

Whitbeck, L. B., \& Hoyt, D. R. (1999). Nowhere to Grow: Homeless and Runaway Adolescents and Their Families. New York: Aldine de Gruyter.

Whitbeck, L. B., Hoyt, D. R., \& Ackley, K. A. (1997a). Abusive family backgrounds and later victimization among runaway and homeless adolescents. Journal of Research on Adolescence, 7(4), 375-392.

Whitbeck, L. B., Hoyt, D. R., \& Ackley, K. A. (1997b). Families of homeless and runaway adolescents: A comparison of parent/caretaker and adolescent perspectives on parenting, family violence, and adolescent conduct. Child Abuse and Neglect, 21(6), 517-528.

Whitbeck, L. B., Hoyt, D. R., \& Yoder, K. A. (1999). A risk-amplification model of victimization and depressive symptoms among runaway and homeless adolescents. American Journal of Community Psychology, 27, 292-296.

Whitbeck, L. B., \& Simons, R. L. (1990). Life on the streets: The victimization of runaway and homeless adolescents. Youth E Society, 22(1), 108-125.

Whitbeck, L. B., \& Simons, R. L. (1993). A comparison of adaptive strategies and patterns of victimization among homeless adolescents and adults. Violence and Victims, 8(2), 135-152. 
Les B. Whitbeck is professor of sociology at the University of Nebraska-Lincoln and faculty affiliate at the Institute for Social and Behavioral Research at Iowa State University. He is principal investigator of the Midwest Longitudinal Study of Homeless Adolescents. His other research programs focus on Native American children and families.

Dan R. Hoyt is a professor of sociology and director of the Bureau of Sociological Research at the University of Nebraska-Lincoln. His research programs focus on risk, deviance, and mental health among high-risk populations.

Kevin A. Yoder is a postdoctoral fellow at the Institute for Health, Health Care Policy, and Aging Research at Rutgers, the State University of New Jersey. His research interests include homeless and runaway youth, mental health, and adolescent suicide.

Anna Mari Cauce is presently the Earl R. Carlson Professor of Psychology and director of the Honors Program at the University of Washington. She has been conducting research for the past 20 years on issues related to normative and nonnormative development in at-risk adolescents, including urban youth of color and homeless adolescents.

Matt Paradise received his undergraduate degree at Stanford University and his graduate degree at the University of Washington, with a concentration in child clinical psychology. He is presently an assistant professor at the University of North Carolina at Greensboro. His research interests include adolescent risk behavior with a special focus on substance use and abuse. 